\title{
Analysis on China's Income Distribution Gap
}

\author{
Linshan Wang \\ Chuanming Liu \\ School of Economics \\ Central University of Finance and Economics \\ 39 South College Road, Haidian District \\ Beijing, P.R. China
}

\begin{abstract}
Since the Economic Reform and Open up, China's income distribution system has gradually realized "mainly according to work, coexist with multiple distribution". However, the income gap now is becoming wider and wider, the unfair distribution of income is more and more obvious, and a series of problems, such as the income gap between urban and rural areas persist for a long time, which will inevitably affect the long-term stable development of the whole economy. Thus, studies on whether it is reasonable to introduce marketization into income distribution system and whether the ownership form of income distribution system hold keys to know the causes of income distribution gap. This paper will explore the influence of public ownership on income distribution through the historical and theoretical deduction, then find the root of income distribution gap.
\end{abstract}

Keywords: Distribution Gap; Ownership; Root Causes

\section{Introduction}

The basic economic system of China has changed with the transformation of economic system from planned economy to market economy, and the income distribution system of residents has also undergone profound changes. In the early days of the founding of the People's Republic of China, China was faced with the form of ownership under the leadership of the state economy, with which made the income distribution field coexist. When the Government proposed the Transitional General Route from 1953 to 1956, the transition goal is mainly focused on the production relations, that is, the socialist transformation of private ownership of means of production, which led to the transition of ownership structure from multiple economic components to single public ownership. During thisperiod, China implemented the "eight-level wage system" in 1953, and began to realize the "single wage system" by drawing on the Soviet model. These two wage reforms made the basic realization of a nationwide wage system based on distribution according to work. With the deepening of the reform, the public ownership and distribution gradually occupied the dominant position, and the income distribution gap between residents was gradually narrowing.

However, after the initial establishment of the socialist system, China has gradually formed a highly centralized planned economy system, regardless of the actual level of its own productivity. The degree of single ownership structure in China was strengthened from 1957 to 1978. At the same time, China began to implement "unified distribution" in the income distribution system. After 1961, even if the central government changed the original policy of "one big two public" to "three-level ownership, team-based ", this system is still combined with the dual urban and rural household registration system, binding farmers in agriculture and collective production, so that their distribution is strictly controlled by the state. This has also induced a big gap on the income distribution between urban and rural residents. The income distribution system trapped under the high degree of public ownership has a very negative impact on the national income distribution of the whole country.

From 1978 to 1988 , the ownership of our country gradually formed the pattern of public ownership economy as the main body and non-public ownership economy as the supplement. During this period, the income distribution system has also been rectified accordingly. The 13th National Congress of the Party held in October 1987 clearly used the concept of "private economy" and made the conclusion that "private economy is a necessary and beneficial supplement to the public ownership economy ". At the same time, the report pointed out:" adhere to distribution according to work as the main body, other distribution methods as a supplement ". At this point, the policy has introduced recognition of legal non-labor income, encouraging some people to get rich first. It can be said that with the addition of non-public ownership, the income distribution system was then proposed to supplement in other ways. 
In October 1992, the 14th National Congress of the Communist Party of China established the goal of my country's economic system reform to establish a socialist market economic system, and clearly put forward the policy of "longterm common development" of various economic components in the ownership structure. Afterwards, the Decision of the Central Committee of the Communist Party of China on Several Issues Concerning the Establishment of a Socialist Market Economic System adopted by the Third Plenary Session of the Fourteenth Central Committee of the Communist Party of China in November 1993 emphasized once again that the distribution of personal income should be based on distribution according to work and multiple distributions. The distribution system with the coexistence of methods clearly put forward the principle of "efficiency first and fairness" for the first time. In September 1997, for the first time, the 15th National Congress of the Party clearly proposed the establishment of a distribution system combining distribution according to work and distribution according to factors of production. This shows that in the process of continuously promoting the common development of multiple ownership systems, the income distribution system is also constantly strengthening and deepening the coexistence of multiple distribution methods. Therefore, it can be seen that the ownership has a profound influence on the income distribution system.

Since 1998, my country has continuously improved and developed a basic economic system with public ownership as the mainstay and common development of various ownership economies. Corresponding to this, in November 2002, the 16th National Congress of the Communist Party of China put forward the ideas of "two unshakable" and "one unity", and established the principle that labor, capital, technology, management and other production factors participate in the distribution according to their contributions To further improve the distribution system with distribution according to work as the main body and multiple distribution methods coexisting. As of October 2007, the 17th National Congress of the Communist Party of China proposed "two equality" on the basis of adhering to the "two unshakable" thinking. The report has an updated statement on deepening the reform of the distribution system, that is, the relationship between efficiency and fairness must be dealt with in the initial distribution and redistribution. Redistribution must pay more attention to fairness. In November 2012, the report of the Eighteenth National Congress of the Communist Party of China called for a comprehensive deepening of the reform of the economic system, and reiterated the decision-making and deployment of the reform of the income distribution system, that is, "strive to achieve the synchronization of residents' income growth and economic development, labor compensation growth and labor productivity Improving synchronization... Both initial distribution and redistribution must balance efficiency and fairness, and redistribution pays more attention to fairness." It can be seen that with the continuous improvement of the ownership system, the formulation of income distribution policies is constantly tilting towards the content of "fairness". In practice, ownership has a profound influence on the income distribution system. In fact, Marx once pointed out in the third volume of "Capital", "Distribution Relations and Production Relations": "The so-called distribution relations are special social forms stipulated by the history of the production process and the reproduction process in which people live in their lives. The relationship between China and China is compatible and is produced by these forms and relations." In the "Critique of the Gotha Program", Marx emphasized again: "Any distribution of consumption materials is nothing but the distribution of production conditions themselves. The distribution of production conditions shows the nature of the production mode itself."

It can be seen from the evolution of my country's ownership and income distribution policies and Marx's guiding program that it is the ownership system that determines the income distribution system. Therefore, when studying the current income distribution gap in China, changes in my country's ownership may play a crucial role. In the following, ownership will be introduced into the theoretical analysis of the income distribution gap in an important form to test whether its impact on the income gap is true.

\section{Literature Review}

As a logical extension of value theory, income distribution theory has always been the research focus on capitalist social economists. Some of the theories and policy recommendations also have a profound impact on the research of China's economists and the reform of China's income distribution system. There are many reasons that affect the income distribution gap both in China and abroad. First of all, economic growth may have a positive (A. Lewis, 1954; Perroti, 1993; Li Hongyi, Zou Hengfu, 1998), negative (Alesina and Rodrik, 1994; Persson and Tabellini, 1994; road sign , 2008), or unfixed impact on the distribution gap (Kuznets, 1955; Alberts and Roberto, 1996; Barro, 2000; Lin Yifu, 1998); Secondly, in terms of fiscal revenue and expenditure, a reasonable tax system (Hayek, 1960), income tax system (M. Friedman, 1962), personal income tax (B. Milanovica, 1999), tax accumulation, and overall taxation (Sonja, 2006) may all reduce the income gap. The government's tax policy adjustment is lagging, which is one of the important reasons why the trend of income distribution expansion cannot be controlled in a timely and effective manner (Li Shi, Zhang Ping, 2000; Zhao Guizhi, 2006). 
Taxation of various countries in fiscal expenditures-The transfer payment system, as an important income redistribution mechanism, has an important contribution to reducing the income distribution gap (Kakwani, 1977; Negri, 1988; Johnson, 2004; Immeroll et al., 2005; Kim and Lambert, 2009 ). However, some transfer payment policies implemented in China may deviate from the original intention of reducing the income gap (Huang Zuhui et al., 2003); thirdly, investment in human capital, especially the general improvement of residents' education degree, has a positive effect on reducing the income distribution gap (J. Meade, 1964; G. Becker, 1966; Winegarden, 1979); fourthly, internationally, financial development may have a non-linearity in income distribution gap (Greenwood and Jovanovich , 1990; Aghion and Bolton, 1997; Matsuyama, 2000), negative (Holden and Prokopenko, 2001; Clarke, Xu and Zou, 2003), or positive (De Gregorio and Kim, 2000; Cagetti and De Nardi, 2005) impact. However, in my country, the impact of financial development level on the urban-rural income gap is not significant (Lu Ming, Chen Zhao, 2004). It can be seen that the existing income distribution gap in China is mainly related to economic growth, taxation system, transfer payment system, human capital status, financial development level and other factors, regardless of whether the economic policy, fiscal policy, etc. are determined by the superstructure. The content is also factor such as the economic development environment and the ability of the workers themselves. The form of ownership in the economic foundation has direct, indirect, and even decisive influences that cannot be ignored.

In Marx's economic theory, ownership theory is at the core. China's ownership system is dominated by public ownership, and the state-owned economy is the representative of public ownership. How to integrate it with the market economy system has always been a fundamental problem that needs to be solved in the reform of the state-owned economy. After 30 years of reform, the state-owned economy represented by state-owned enterprises has already got rid of the predicament, but many development issues, including how to coordinate national income distribution, still need to be resolved. The negative impact on income distribution involves poor macroeconomic policy formulation or implementation in many top-level designs.

In China, in the process of macroeconomic policy formulation and implementation, there are many shortcomings in the income distribution system that need to be improved: firstly, the gap in the income distribution of our residents is mainly caused by institutional transformation. The structure has changed. On the contrary, the gap in income distribution among residents has shown an increasing tendency(Li Shi et al., 1999). Secondly, during the transition period, power entered the field of initial distribution in the market, undermining the principles of equal opportunities and equal rights in market competition, resulting inan unfair income`s distribution(Weighing, 2005). The reform of the income distribution system lags behind, leading to a serious imbalance in the benefits of the first distribution, weak or even reverse adjustment of redistribution, and a limited function of the third distribution, which continues to widen the income distribution gap (Peng Teng, 2008). Finally, the economic development strategy formulated by the government runs counter to the comparative advantages of regional production factors. In order to achieve its goal, it interferes with the normal operation of the market, restricting the technological progress and productivity improvement of various provinces and regions, and ultimately leading to the gap in economic growth performance among regions has widened (Lin Yifu, Liu Peilin, 2003).

To sum up, in the face of the current situation of expanding national income distribution under our current income distribution system, we must grasp the root cause of the problem and solve it from the source. The reason why China's income distribution policy has many shortcomings, the reason is that under the socialist market economy with public ownership as the main body, China's public ownership policy still has unclear and clear problems, which in turn affects China's income distribution system and income distribution gap.

\section{Conclusions and Policy Implications}

\section{At present, there are diverse reasons for the income distribution gap in China:}

Theoretically, as we all know, in Marx's labor theory of value, the value of commodities is created by labor, and income distribution is the distribution of the value created by labor. The labor force can create a new value greater than its own value as a special commodity. This new value can be decomposed into labor value and surplus value. The surplus value is freely occupied by capitalists, and is further decomposed into profit, interest and land rent, and paid to the owners in the form of profit and land rent. Therefore, wages, profits, and land rents are all kinds of income. Capitalist distribution is the division of surplus value created by hired workers. In the process of introducing a market economy, China has also faced similar problems regarding wealth distribution. When the distribution according to work was implemented in the original public ownership economy, only the residual value portion was distributed. However, in the process of introducing the market economy, the distribution of wealth was carried out in the entire range including constant capital value (c), variable capital value (v) and surplus value (m). 
Since the value of constant capital accounts for the largest proportion of commodities value, this part is often owned by a few people, and most people can only get a smaller part. This can be regarded as the internal reason for the widening income distribution gap.At the same time, Marx believes that the nature of the ownership of the means of production determines the nature of distribution, but it does not directly determine the mode of distribution. The mode of distribution is determined by the way of resource allocation; first of all is the distribution of production tools and labor. This allocation of production factor resources determines the outcome of social product distribution.

The basic economic system is the direct cause that affects the objective existence of the income distribution system. The public ownership of socialist means of production is a prerequisite for distribution according to work. The establishment of public production has realized the equality of laborers in the possession of means. Within the public ownership system, people cannot use the publicly owned means of production to freely occupy the labor achievements of others, so that consumer goods can be distributed in a way that benefits the laborers. However, at this stage, our country is implementing a basic economic system of "public ownership as the mainstay and the development of a variety of ownership economies", which has developed a socialist market economy. And the impact of marketization on income distribution also cannot be underestimated: on one hand, the distribution according to work realized by the market pricing mechanism combines simple and complex labor, skilled and unskilled labor, and pioneering and nonpioneering labor. Strict distinction, and give different labor remuneration to labor suppliers of different natures, which leads to the gap in the initial distribution stage; on the other hand, factors of production have a more cumulative effect than labor, so whether it is based on capital, technology, land,

the distribution rate of production factors such as labor force to production or distribution according to the degree of laborers' ownership of various production factors will increase the income gap between people. In addition, there are differences in personal talents, working abilities, workers' physical strength, and brain power mentioned in the literature review, and in the development of a market economy, whether different workers can seize opportunities and bear economic risks are not all the same, so there will be differences in distribution, which is also an inevitable result of the market economy distribution system.

When introducing the economic principles of "imports" from abroad, several popular theories in our country affected our timely management of the income gap. Firstly, it is believed that widening the income distribution gap can improve efficiency, but this assumption has not been tested in theory or in practice; secondly, the perfect market mechanisms can eliminate unfair income distribution. In fact, in the process of continuously advancing the market economy in developed countries, including the United States, even though they have the most efficient market system, there is still great income inequality; thirdly, they believe that economic growth will eventually reduce income gap. However, from the analysis results of the impact of economic growth on income distribution in the literature review, we can see that there are many possibilities for the impact of economic growth on income distribution, rather than a single negative correlation; fourthly, that labor wages are determined by market supply and demand. From the planned economy to the market economy, the distribution policy according to the combination of distribution according to work and distribution according to factors of production, our country's wage theory is mainly affected by the following three distribution theories: The first one is the theory of supply and demand distribution. Neoclassical economics attempts to price the factors of production through this theory and distribute them before production. The market price of labor in China is essentially the same, except that changes in relative prices are more detrimental to laborers. The second one is the theory of distribution of marginal productivity. This kind of ex-post distribution based on laborer's contribution proved to be not operable in later practice, and was classified as a typical "blackboard economics". The third one is the comparative advantage theory of cheap labor. This was originally the result of domestic scholars stealing "commodities" into "labour" in Ricardo's comparative advantage theory. Internationally and domestically, the free flow of labor is restricted, making China's labor remuneration relatively low in the initial distribution.

In practice, the existence of various factors has led to the failure to improve the income distribution gap in China. Specifically, first of all, in factor prices, there is an underestimation of state-owned assets and management's nonstandard acquisitions, which will widen the gap between state-owned enterprises and other enterprises; at the same time, as agents rather than owners, government has not benefited from the ownership or control of public resources, and public resource gains have been seized by a small number of companies that have obtained the right to use them; land pricing, especially farmers' land expropriation pricing, is unreasonable. In contrast, real estate development and other industries have made huge profits, resulting in an unreasonable high and low incomes class. Secondly, in the distribution of enterprises, the profit distribution system and the surrender system of state-owned enterprises are unreasonable. The transformation of state rights and interests into high incomes of enterprise executives and employees within the system will also widen the income distribution gap. 
During the reform and opening up process, enterprise agents there is opportunism in the behavior of leading companies when they embark on internationalization. Reforms have given executives the opportunity to obtain high bonuses, stock options, and other "wage increases." These increases in income are not shared with workers, which will inevitably affect income distribution. Thirdly, the state has allowed some policies and systems to widen the income distribution gap, such as setting policies to encourage some regions and individuals to get rich first, but lacks prior arrangements and post-action actions to help the rich get rich. Policy restrictions will continue to widen the income distribution gap. Finally, in the 1990s, the social structure showed a tendency to stereotypes, which was not conducive to labor mobility and caused a monopoly of modern wealth.

It can be seen from this paper that ownership does indeed have an important influence on the generation and expansion of the modern income distribution gap. Even the factors that influence income distribution derived from many theoretical studies are only the transmission factors of ownership's influence on income distribution. Therefore, the impact of changes in ownership on income distribution is fundamental. To solve the current problem of income distribution gap in China, we should start from the source, accurately position the ownership policy, and make the right decisions to achieve good and rapid development of the national economy. Orientation, reasonable income distribution while developing the economy, so that every China's citizen can enjoy the benefits brought by economic development in a fair and equal way. China's policy practice is compatible with the new income distribution system and supplemented in order to prevent the negative impact of changes in the distribution system, the anti-monopoly and antiirrational auxiliary policies do not seem to effectively restrain the expansion of the income distribution gap. This has also prompted us to consider making deeper and more thorough reforms, such as changing state-owned companies to state holdings, among a series of state-managed agencies, including state-owned enterprises. In short, under the socialist marketization and in the basic economic system with public ownership as the main body, we should take advantage of public ownership, actively and flexibly reform, and give full play to the advantages of state-owned, collective, and mixed ownership enterprises in order to truly narrow the present gap in income distribution.

\section{References}

Alfred, Guo Qingwang, Yang Tieshan translation.(2000).Fiscal policy and economic growth. Beijing: Economic Science Press.

Arthur. Okun, translated by Wang Benzhou. (1987).Equality and efficiency: a major choice. Beijing: China Publishing House.

Arthur. Lewis, translated by HeBaoyu. (1988).Development plan. Beijing: Beijing University of Economics Press.

Allen. Buchanan, Liao Shenbai, Xie Dajing.(1991). Ethics, efficiency and market. Beijing: China Social Sciences Press.

Clarke, Chen Fusheng, Chen Zhenche. (1981). The distribution of wealth. Beijing: Commercial Press.

David. Ricardo.(1976).Principles of Taxation in Political Economy. Beijing: Commercial Press

Gu Yaguang. (2010).The status, causes and governance measures of the income distribution gap in China. Marxism Research. 4,64-74.

Hayek, translated by Deng Zhenglai. (1997). Principle of Free Order. Beijing: Sanlian Bookstore.

Huang Zuhui.(2007). Research on the income gap of China's residents in the transition period. Zhejiang: Zhejiang University Press

Karl. Menger, translated by Liu Bangao.(2001). Principles of National Economics. Shanghai: Shanghai People's Publishing House.

Leon. Works by Valras, translated by Cai Shoubai.(1987). Essentials of Pure Economics. Beijing: Commercial Press.

Liu Yang.(2013). Research on the fiscal policy to adjust the income distribution gap of China's residents. Beijing: Institute of Fiscal Science, Ministry of Finance.

Marx, GuoDali, Wang Yanan. (1975).Capital Theory. Beijing: People’s Publishing House.

Max. Weber, translated by Lin Rongyuan. (1997).Economy and Society. Beijing: Commercial Press.

Marshall, translated by Zhu Zhitai.(1964). Principles of Economics (Part 1). Beijing: Commercial Press.

Marshall, translated by Zhu Zhitai.(1964). Principles of Economics (Part 2). Beijing: Commercial Press.

Quenai Works, Wu Feidan, Zhang Cao Niu Translation. (1979). Selected works of Quenei Economics. Beijing: Commercial Press, 10-15.

Sang Donghua. (2010). The evolution of the party's ownership policy since the founding of New China and the changes of my country's ownership structure. Research on the History of the Communist Party of China, 7,5159. 